\title{
Mobile phone usage in patients with type II diabetes and their intention to use it for self-management: a cross-sectional study in Iran
}

Fatemeh Rangraz Jeddi ${ }^{1,2}$, Ehsan Nabovati ${ }^{1,2^{*}}$ (D), Rahele Hamidi ${ }^{2,3}$ and Reihane Sharif ${ }^{2,3}$

\begin{abstract}
Background: Mobile health has potential for promotion of self-management in patients with chronic diseases. This study was conducted to investigate smartphone usage in patients with type II diabetes and their intention to use it for self-management.

Methods: This cross-sectional study was conducted in 2018 with 176 patients with type II diabetes visiting a specialized diabetes clinic or one of two endocrinology and metabolism specialists in north of Iran. Data were collected using a validated questionnaire containing items on demographic characteristics, disease information, use of mobile phones, smartphones and the internet, and intention to use mobile phones for diabetes selfmanagement.

Results: The majority of the participants had mobile phones (94.9\%), smartphones (61.1\%), and daily access to the internet (81.3\%), and used phones two hours per day on average (80.1\%). They mostly used mobile phones to contact friends (89.2\%) and search for information (50.6\%), and their greatest intention for using smartphones and the internet for self-management was related to dietary planning (96\%), checking blood glucose (90.9\%), and contacting specialists (87.5\%). Younger participants were more interested in using smartphone applications (apps) $(P<0.001)$. About half of the participants argued that using apps can be interesting $(54 \%)$ and useful $(50 \%)$ for diabetes management, and intended to use apps much more in future (48.3\%).

Conclusions: The majority of patients with type II diabetes are inclined to use mobile phone and the Internet, especially to plan their diet, check blood glucose, and contact their doctors. The present study provides valuable information for designing and implementing interventions based on mHealth to promote self-management in type II diabetes.
\end{abstract}

Keywords: Mobile health, Smartphone, Self-management, Type II diabetes

\section{Background}

Type II diabetes mellitus (T2DM), compromising the majority of patients with diabetes, has turned into a major health concern throughout the world [1]. According to the WHO estimates (2016), there are 422 million patients with diabetes over 18 years old worldwide [2],

\footnotetext{
* Correspondence: Nabovati@kaums.ac.ir

${ }^{1}$ Health Information Management Research Center, School of Allied Health Professions, Kashan University of Medical Sciences, Pezeshk Blvd, 5th of Qotbe Ravandi Blvd-Pardis Daneshgah, Kashan 8715973449, Iran

${ }^{2}$ Department of Health Information Management \& Technology, School of Allied Health Professions, Kashan University of Medical Sciences, Kashan, Iran Full list of author information is available at the end of the article
}

which will increase to 552 million patients by 2030 [3]. This increment is higher in developing countries than in developed countries [4]. A meta-analysis has shown that the prevalence of T2DM in Iran is higher than other developing countries [5]. The prevalence of diabetes in this country was reported about $10.3 \%$ in 2016 [6]. Diabetes is known as the seventh cause of death in the world [7] and has many complications including cardiovascular, cerebrovascular, peripheral vascular, retinopathy, nephropathy, diabetic foot, amputation, and depression [8]. Managing chronic diseases is challenging as diabetic patients require knowledge and skills in understanding the

(c) The Author(s). 2020 Open Access This article is distributed under the terms of the Creative Commons Attribution 4.0 International License (http://creativecommons.org/licenses/by/4.0/), which permits unrestricted use, distribution, and reproduction in any medium, provided you give appropriate credit to the original author(s) and the source, provide a link to the Creative Commons license, and indicate if changes were made. The Creative Commons Public Domain Dedication waiver (http://creativecommons.org/publicdomain/zero/1.0/) applies to the data made available in this article, unless otherwise stated. 
needs of medical care, and thus diabetes selfmanagement is crucial, as part of a patient's commitment to preventing disease complications [9].

Improving self-management behaviors is the first step toward helping patients with diabetes to better control their disease [10]. Successful management of diabetes depends on the individual's ability to have effective selfmanagement behaviors such as proper use of the prescribed medications, adherence with dietary and activity regimens, self-monitoring, and coping with the psychological impact of living with a chronic disease [11]. However, many patients with diabetes are faced with several barriers that interfere with self-management in achieving glycemic control, the body fat and weight, controlling blood pressure and blood fat, and having an optimizing diet $[12,13]$. Given the high and increasing prevalence of diabetes and the importance of self-management, inexpensive and practicable self-management methods should be considered for these patients [14]. It has been shown that diabetes self-management can be improved with mobile phone interventions since they have potential to support therapy management, improve therapy adherence, and prevent disease complications [15].

Currently, mobile-based educational interventions are fairly new and can switch the focus of care and treatment from the clinic to the patient's daily life [16]. Not only have these interventions improved clinical outcomes and self-management skills, but have also reduced the health-related costs and the frequency of the patient visits to the clinic [17-19]. Interventions based on information and communication technology including mobile health technology (mHealth), have a good potential for promoting self-management through behavior change supports (such as providing information, training, and reminders) $[20,21]$. mHealth is a part of electronic health (eHealth), and implies using mobile phones and wireless technologies to improve health-related services [22]. Telemedicine tools (e.g. text messaging) and smartphone applications (apps) can facilitate and improve the patient-provider communication [23]. Ease of use and portability are the potential benefits of mHealth tools for prevention, diagnosis, and treatment of diseases, and also to enhance access to health services and reduce costs [24].

Despite its potential benefits and increasing interest in it, mHealth has not been implemented much in practice [25]. One of the key components for successful implementation of any mobile health intervention is its users' positive attitude toward the use of this technology [26, 27]. According to the review of literature, several studies have already investigated the use of mHealth applications and the attitude of patients with diabetes on their use in developed countries [28-30]. In Canada, Dobson et al. (2015) investigated the current use and attitude of patients with T2DM on the use of the Internet and mobile phone apps in diabetes self-management, and reported that patients, especially younger ones, are more interested in adopting these technologies for their diabetes self-management [29]. In England, Humble et al. (2016) investigated the use and intention of patients with diabetes regarding mHealth technology for self-management and argued that younger patients use the Internet and apps more, and are interested in using apps for managing their diabetes [30]. A study conducted by Boyle et al. (2017) in New Zealand, only investigated the diabetes patients' use of mobile phone apps and their features. Their results showed that $80.4 \%$ of respondents (56\% with T1DM, 44\% with T2DM) did not use diabetes apps [28]. To our knowledge, there is limited evidence on the use of mHealth applications and the attitude of patients with T2DM on their use in developing countries. In Iran, Jafari et al. (2015) only studied Internet access and Internet-related issues of patients with T2DM, and reported that patients had poor level of the Internet use and the Internet was not the main diabetes-related information source [31].

The number of smartphone apps relating to selfmanagement of chronic diseases, especially diabetes, is increasing [32]. In contrast to developed countries such as the USA and England, in Iran as a developing country, no study has yet investigated the attitude and intention of patients with T2DM regarding the use of mobile phone capabilities (such as the Internet and apps) for self-management. Thus, the present study aimed to investigate the use of mobile phones in patients with T2DM and their intention to use them for selfmanagement.

\section{Methods}

\section{Study design and setting}

The present cross-sectional study was conducted in spring 2018 in the city of Ardabil in northwestern Iran. Participants selected by convenience sampling method, included patients with T2DM visiting Imam Khomeini hospital's diabetes clinic or one of two endocrinology and metabolism clinics. Patients with at least primary school education whose diabetes had been confirmed by a specialist qualified for participation. Patients unwilling to take part in the study were excluded. The required sample size was found 173 patients based on a similar study [29], and taking into account $93 \%$ daily use of the Internet in that study, 99\% confidence, and maximum error of 0.05 , and using $n=\left(Z^{\wedge} 2 p q\right) / d^{2}$.

\section{Questionnaire}

Data were collected using a questionnaire developed according to Dobson et al. study [29] and modified based on the study objectives, and views expressed by a health 
information management expert, a medical informatics expert, and an endocrinologist, who confirmed its face validity. Content validity of the questionnaire was assessed by 12 experts (in health information management, medical informatics, and endocrinology). The item content validity (i.e. relevance and clarity) plus comprehensiveness of the entire tool was assessed according to the views expressed by the mentioned experts in the form of Likert scale (from unfavorable $=1$ to totally favorable $=4$ ) [33]. Content validity was assessed for each item based on content validity index (CVI), such that items with $\mathrm{CVI}<0.7$ were revised and modified. Also, content validity ratio (CVR) was found according to Lawshe Table, such that items with $\mathrm{CVR}<0.56$ were eliminated. Reliability of the questionnaire was assessed by split-half and Cronbach's alpha method (0.82).

After validation, the final questionnaire (Additional file 1) contained 30 items in five parts, including demographic details (5 items), disease information (5 items), the use of mobile phones and the Internet (6 items), intention to use mobile phone apps to control diabetes (11 items), and general explanations (3 items). In the demographic part, items were about gender, age, place of residence, education and occupation. In disease information part, participants were asked of their height, weight, duration of diabetes and other chronic diseases. They were also asked about diabetes management difficulties. These difficulties included choosing an optimizing diet, adequate physical activity, communication with the doctor and other healthcare providers, relationship with friends and family, blood glucose diary, and lack of clear and precise diabetes management goals. In the use of mobile phones and the Internet, participants were asked if they had a mobile phone and access to the Internet, and how many hours per day they used them. In this part, participants were also asked about what they used mobile phones for. In the part of intention and attitude about using the Internet and mobile phones for managing diabetes, participants were asked about services they required for managing their disease. The patients' use of smartphone apps to manage their disease was assessed with seven questions: "For me, using smartphone apps for self-management can be a good idea, enjoyable, easy, exciting, interesting, helpful, and economical". These questions are based on a 5-point Likert scale from very bad $=1$ to very good $=5$. Participants were also asked about their certainty about using smartphone apps for the disease management, and their intention to use apps in future was assessed by a question based on a 5point Likert scale (from no intention $=1$ to very high intention $=5$ ).

\section{Data collection}

The present study was approved by the ethics committee of Kashan University of Medical Sciences
(IR.KAUMS.NUHEPM.REC.1396.21). To collect data, the researcher visited the diabetes clinic and specialists' offices, and briefed the patients in the waiting room on the study objectives and how to complete the questionnaire. The questionnaires were distributed among the patients after they were reassured of confidentiality of data and signed written informed consents. The questionnaires were completed by the patients in researcher's presence, so that the researcher could resolve any ambiguities. A total of 210 patients with T2DM attending the clinic and doctor's offices were identified, of whom 176 were willing to complete the questionnaire, with a response rate of 83.8\%. All 176 participants completed the questionnaires.

\section{Statistical analysis}

Data were analyzed by using SPSS version 22.0. First, the percentage and frequency of demographic information, the use and intention to use mobile phones and the Internet by participants, and difficulties in selfmanagement were determined. The overall attitude score was found by combining values of scales relating to attitude (7 questions) and finding their mean and standard deviation. The intention score was determined using one question. The body mass index (BMI) was calculated based on the details of weight and height reported by patients. The relationships between demographic information and attitude, and intention and confidence were assessed using Chi-square or Fisher's exact test. $P<0.05$ was considered as the level of significant.

\section{Results}

Table 1 presents participants' demographic and disease details. Of the 176 participating patients, 97 (55.1\%) were women. Participants' mean age was 53.18 years $(\mathrm{SD}=$ 15.5), the majority were did not complete high school (56.8\%), and 152 (86.4\%) lived in the city. Eighty-two patients had other chronic diseases (46.6\%), of whom, 15 had hypertension, 8 had cardiac problems, and 4 had asthma, and the rest had other diseases including neurological, gastric, thyroid, kidney, and high blood lipids. Participants' mean BMI was $28.42 \mathrm{~kg} / \mathrm{m}^{2}$ (SD = 5.1).

Table 2 shows general findings about participants' use of mobile phone and the Internet and their intention to use them for controlling their diabetes. Of the 176 participants, 167 (94.9\%) had mobile phones, 109 (61.9\%) had smartphones, and $143(81.3 \%)$ had daily Internet access. Most of the participants spent more than two hours per day using mobile phones (80.1\%) and the Internet (56.8\%). Participants mostly used their mobile phones to contact friends $(89.2 \%)$ and search for information (50.6\%). They used their mobile phones the least for sending and receiving emails $(9.1 \%)$, and shopping online (15.9\%). Mobile phones and the Internet were 
Table 1 Participants' demographic and disease details $(n=176)$

\begin{tabular}{|c|c|c|c|c|}
\hline \multicolumn{2}{|c|}{ Demographic details } & \multirow{2}{*}{$\begin{array}{l}\text { Frequency } \\
97\end{array}$} & \multirow{2}{*}{$\begin{array}{l}\text { Percentage } \\
55.1\end{array}$} & \multirow[t]{2}{*}{ Mean \pm SD } \\
\hline Gender & Female & & & \\
\hline & Male & 79 & 44.9 & \\
\hline Age & & & & $53.18( \pm 15.05)$ \\
\hline \multirow[t]{5}{*}{$\begin{array}{l}\text { Education } \\
\text { level }\end{array}$} & $\begin{array}{l}\text { Below high } \\
\text { school diploma }\end{array}$ & 100 & 56.8 & \\
\hline & $\begin{array}{l}\text { High school } \\
\text { diploma }\end{array}$ & 40 & 22.7 & \\
\hline & $\begin{array}{l}\text { Advanced } \\
\text { diploma }\end{array}$ & 7 & 4 & \\
\hline & $\begin{array}{l}\text { Bachelor's } \\
\text { degree }\end{array}$ & 20 & 11.4 & \\
\hline & $\begin{array}{l}\text { Master's degree } \\
\text { and higher }\end{array}$ & 9 & 5.1 & \\
\hline \multirow[t]{6}{*}{ Occupation } & Retired & 21 & 11.9 & \\
\hline & $\begin{array}{l}\text { Full-time } \\
\text { employment }\end{array}$ & 30 & 17 & \\
\hline & $\begin{array}{l}\text { Part-time } \\
\text { employment }\end{array}$ & 8 & 4.5 & \\
\hline & Housewife & 63 & 35.8 & \\
\hline & Unemployed & 7 & 4 & \\
\hline & Other & 47 & 26.7 & \\
\hline \multirow{2}{*}{$\begin{array}{l}\text { Place of } \\
\text { residence }\end{array}$} & Urban & 152 & 86.4 & \\
\hline & Rural & 24 & 13.6 & \\
\hline \multirow[t]{5}{*}{$\begin{array}{l}\text { Duration of } \\
\text { the disease }\end{array}$} & $\begin{array}{l}\text { Less than } 6 \\
\text { months }\end{array}$ & 35 & 19.9 & \\
\hline & $\begin{array}{l}6 \text { months to } \\
\text { one year }\end{array}$ & 27 & 15.3 & \\
\hline & 1 to 3 years & 38 & 21.6 & \\
\hline & 3 to 5 years & 25 & 14.2 & \\
\hline & $\begin{array}{l}5 \text { years and } \\
\text { longer }\end{array}$ & 50 & 28.4 & \\
\hline \multirow{3}{*}{$\begin{array}{l}\text { Other } \\
\text { chronic } \\
\text { diseases }\end{array}$} & Yes & 82 & 46.6 & \\
\hline & No & 92 & 52.3 & \\
\hline & Do not know & 2 & 1.1 & \\
\hline$B M l^{\mathrm{a}}$ & & & & $28.42( \pm 5.1)$ \\
\hline
\end{tabular}

${ }^{\mathrm{a} B M I}$ Body mass index

used by most participants for planning their diet (96\%), checking blood glucose and other relevant clinical parameters (90.9\%), and contacting their physicians (87.5\%).

Table 3 shows participants' attitude and intention regarding the use of smartphone apps for diabetes selfmanagement. Half of the participants stated that using apps to help manage diabetes can be interesting (54\%) and useful (50\%), 85 (48.3\%) stated that they intended to use apps for diabetes control "much more" in future (48.3\%), and 57 (32.4\%) stated that they were 61 to $80 \%$ confident that they would use apps for controlling their diabetes.
Table 4 shows the results relating to participants' problems in diabetes self-management. The majority of the participants stated that their problems are mostly related to choosing an optimizing diet (81.8\%), adequate physical activity (69.9\%), and blood glucose diary (64.8\%).

Table 5 shows the correlation of participants' demographic characteristics, attitude and intention to use smartphone apps for diabetes self-management and their Internet and mobile phone use. Compared to older participants, younger ones were significantly more interested $(P<0.001)$ in using apps, and had greater intention $(P=0.012)$ and higher confidence $(P<0.001)$ in using these tools in future. Moreover, younger participants spent significantly more time per day using their mobile phones $(P<0.001)$.

Participants' gender had no significant relationship with attitude toward, intention to, and confidence in using smartphone apps and also daily use of the Internet and mobile phones. Patients with higher education levels had significantly better attitude toward $(\mathrm{P}<0.001)$ and greater confidence $(\mathrm{P}<0.001)$ in using smartphone apps, and also higher use of mobile phones $(P=0.022)$ and the Internet $(P=0.001)$. A significant difference was observed between patients' occupation and confidence $(\mathrm{P}<$ 0.001) in using smartphone apps, such that the post hoc test results showed that participants in full-time employment had greater confidence in using apps. Patients with T2DM for a longer time had poorer attitude toward $(P=0.033)$ and less confidence in $(P=0.007)$ using apps compared to those having T2DMfor a shorter time. On the other hand, the Internet use significantly increased in those who had diabetes for a longer time $(P=0.003)$.

According to the results, 171 (97.2\%) of the participants stated that they wished to receive help from other family members (namely spouse and children) if they were unable to use mobile phones for self-management purposes. Also, 125 (71\%) wished to take part in future studies assessing the effect of using apps in diabetes control.

\section{Discussion}

\section{Principal findings}

The majority of the participants in the present study had mobile phone and access to the Internet. More than half of the participants spent two hours a day on average using their mobile phone and the Internet, and mobile phones were mostly used to contact friends and search for information. The majority of the participants intended to use mobile phones and the Internet for planning their diet, checking blood glucose and other clinical parameters, and contacting their doctors. Half of the participants stated that using smartphone apps can be interesting and help them manage their diabetes, and 
Table 2 Frequency percentage of participants' use and intention to use mobile phone and the Internet $(n=176)$

\begin{tabular}{|c|c|c|c|c|}
\hline \multirow[t]{2}{*}{ Question } & & \multicolumn{3}{|c|}{ Number (percentage) } \\
\hline & & Yes & No & Do not know \\
\hline \multirow[t]{3}{*}{ Current technology use } & Having a mobile phone & $167(94.9)$ & $9(5.1)$ & - \\
\hline & Having a smartphone & $109(61.9)$ & $67(38.1)$ & - \\
\hline & Having daily access to the Internet & $143(81.3)$ & $33(18.8)$ & - \\
\hline \multirow{7}{*}{$\begin{array}{l}\text { Intention to use mobile phone and the Internet for } \\
\text { diabetes control }\end{array}$} & Dietary planning & $169(96)$ & $4(2.3)$ & $3(1.7)$ \\
\hline & Checking blood glucose and other parameters & $160(90.9)$ & $4(2.3)$ & $12(6.8)$ \\
\hline & Contacting specialists & $154(87.5)$ & $5(2.8)$ & $17(9.7)$ \\
\hline & $\begin{array}{l}\text { Using text messages as a reminder for diabetes } \\
\text { self-management }\end{array}$ & $145(82.4)$ & $4(2.3)$ & $27(15.3)$ \\
\hline & Planning physical activity & $143(81.3)$ & $9(5.1)$ & $24(13.6)$ \\
\hline & $\begin{array}{l}\text { Contacting other healthcare providers } \\
\text { (nutritionist and nurses) }\end{array}$ & $100(56.8)$ & $20(11.4)$ & $56(31.8)$ \\
\hline & Contacting other patients with diabetes & $45(25.6)$ & $63(35.8)$ & $68(38.6)$ \\
\hline
\end{tabular}

intended to use apps "very often" for diabetes control in future. About a third of the participants stated that they had confidence in using apps for diabetes control. The participants considered choosing the right diet, adequate physical exercise, and blood glucose diary as their main problems.

The results showed that a significant number of the participants had mobile phones and smartphones. Similarly, Boyle et al. [28] in New Zealand (2017), Humble et al. [30] in the UK (2015), and Dobson et al. [29] in Canada (2015) reported a significant number of patients with diabetes had access to mobile phones and smartphones. Also, a significant number of the participants in the present study had access to the Internet, and more than half of them used the Internet for two hours a day on average. Similarly, in a study by Dobson et al. [29] on 44 patients with T2DM, more than $90 \%$ of the participants had access to the Internet. The results of this study in a developing country compared to other studies in developed countries showed that there was no significant difference in terms of mobile phone and internet access. The results of the present and similar studies $[28-30,34]$ confirm that the increasing use of communication technologies (such as smartphones and the Internet) has created the opportunity to provide

Table 3 Mean and standard deviation of participants' attitude and intention to use smartphone apps to control their diabetes $(n=176)$

\begin{tabular}{ll}
\hline Question & Mean (out of 5) \\
\hline $\begin{array}{l}\text { Patients' attitude toward using apps for } \\
\text { diabetes control }\end{array}$ & $4.18 \pm 0.68$ \\
$\begin{array}{l}\text { Patients' intention to use apps for } \\
\text { diabetes control in the future }\end{array}$ & $4.34 \pm 0.75$ \\
\hline
\end{tabular}

${ }^{a}$ Attitudes \& Intention rated $1-5$ patients with chronic diseases with health information, especially self-management information.

The results showed that a significant number of the participants, who were mostly living in urban area, had mobile phones and smartphones. Similarly, in the studty by Hodge et al. [35], urban patients with T2DM in Australia had more use of Internet and mobile than rural residents. The lower Internet use associated with rural residence was explained by limited access to the Internet and to digital technology and differences in education and included personal limitations, such as a lack of skills, experience and familiarity in using online technologies [36, 37].

The majority of the participants stated their intention to use mobile phones and the Internet, especially for planning their diet, checking blood glucose, and contacting their doctors, which agrees with the findings of a study conducted in Canada [29]. More than half of the participants had a positive attitude toward, and the majority were confident in using apps for diabetes

Table 4 Frequency percentage of participants' problems in diabetes self-management

\begin{tabular}{lll}
\hline Diabetes self-management problems & \multicolumn{2}{l}{ Number (percentage) } \\
\cline { 2 - 3 } & Yes & No \\
\hline Choosing the right diet & $144(81.8)$ & $32(18.2)$ \\
Doing adequate physical activity & $123(69.9)$ & $53(30.1)$ \\
Blood glucose diary & $114(64.8)$ & $62(35.2)$ \\
$\begin{array}{l}\text { Contacting the physician } \\
\text { Not having clear and precise goals for }\end{array}$ & $76(48.9)$ & $90(51.1)$ \\
diabetes management & $77.7)$ & $99(56.3)$ \\
$\begin{array}{l}\text { Contacting other healthcare providers } \\
\text { (nutritionists and nurses) }\end{array}$ & $37(21)$ & $139(79)$ \\
$\begin{array}{l}\text { Contacting friends and family } \\
\text { (for diabetes control) }\end{array}$ & $11(6.3)$ & $165(93.8)$ \\
\hline
\end{tabular}


Table 5 Correlation between participants' demographic characteristics, attitude and intention in relation to the use of smartphone apps for diabetes self-management

\begin{tabular}{|c|c|c|c|c|c|}
\hline Demographic variables & Attitude & Intention & Confidence & Internet use & Mobile use \\
\hline Age & $-0.373^{b}$ & $-0.190^{\mathrm{a}}$ & $-.470^{b}$ & $.290^{\mathrm{b}}$ & $-.249^{b}$ \\
\hline Gender & 0.092 & 0.066 & .116 & -.075 & .030 \\
\hline Education & $0.254^{b}$ & 0.083 & $.387^{\mathrm{b}}$ & $.245^{\mathrm{b}}$ & $.172^{\mathrm{a}}$ \\
\hline Occupation & $-0.157^{\mathrm{a}}$ & -0.044 & $-.229^{b}$ & .074 & -.053 \\
\hline Duration of diabetes & $-0.161^{\mathrm{a}}$ & -0.060 & $-.203^{b}$ & $.225^{\mathrm{b}}$ & -.072 \\
\hline Place of residence ${ }^{c}$ & - & - & - & - & - \\
\hline
\end{tabular}

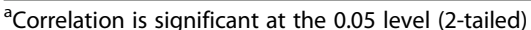

${ }^{\mathrm{b}}$ Correlation is significant at the 0.01 level (1-tailed)

${ }^{\mathrm{c}}$ This comparison was not applicable

management, and half of the participant stated their intention to use apps in future for diabetes control. These results concur with those obtained by Conway et al. [38] in the UK (2015). Boyle et al. [28] cited that patients with diabetes expressed the following reasons for not using diabetes-related apps: not knowing such apps existed or their potential benefits, doctors did not recommend them to patients, patients did not feel confident without apps, and felt tired after using apps. According to Dobson et al. [29], the reasons for not using apps included the patients' unawareness of the availability of such apps and lack of confidence in them. However, in a study by Jenkins et al. [39], 75\% of patients with stroke had the intention to use mHealth interventions and $83.3 \%$ had confidence that this technology could be an effective tool for their communication with healthcare providers. Hofstede et al. (2014) [27] reported the main reason for a positive attitude of patients with asthma and chronic obstructive pulmonary disease toward using apps as being time-saving and user-friendly, and supporting planned care when required.

In the present study, the most common problems that patients with T2DM faced in self-management were choosing the right diet, inadequate exercise, and blood glucose diary. Similarly, Dobson et al. [29] reported choosing the right diet, inadequate exercise and following up blood glucose level as the most common problems of patients with T2DM. Given the importance of self-management in patients with T2DM and availability of diabetes-related apps with features for monitoring blood glucose, physical activity, and dietary management [40], several studies have investigated the effectiveness of such tools on diabetes-related outcomes [41-43]. These studies have shown that apps can improve adherence with activities relating to diabetes management such as regular intake of medication and insulin shots, blood glucose self-monitoring, diet, and physical activity.

In agreement with Dobson et al. study [29], the relationships of age and duration of T2DM with patients' attitude and intention about using apps, and the use of mobile phones and the Internet were significant. Younger patients were more interested in using apps and had greater intention to and confidence in using them in future. Also, patients with diabetes for longer had poorer attitude toward and confidence in using apps. In the present study, patients with higher education levels had a better attitude toward and confidence in using apps, and used mobile phones and the Internet more often. These results agree with those obtained in studies by Song et al. [44] in the USA (2013) on pregnant women, and Jafari et al. [31] in Iran (2015) in patients with T2DM. A review study showed that most pregnant women with higher education considered using the Internet useful and reliable [45]. These results may be due to the fact that patients with higher education levels have greater reasoning and critical thinking skills compared to others, and therefore have better judgment and higher confidence in mHealth technologies.

To our knowledge, the present study is the first study in a developing country to investigate the attitude and intention of patients with T2DM about using the Internet and smartphone apps for diabetes self-management. The present study was conducted on a sample of $176 \mathrm{pa}-$ tients in a city, which may be considered as a limitation. Given that the majority of patients with T2DM were in older age group, with low education level, participants' old age and poor education level can be considered another limitation.

According to the present study results, patients with a positive attitude toward and intention to use the Internet and smartphone apps for self-management were the younger ones, with higher education levels and a shorter period with diabetes. In the present study, the self-management problems of patients with T2DM were identified. It is recommended that diabetes self-management features of smartphone apps be designed according to the patients' conditions and needs. As suggested in Dobson et al. study [29], future studies should identify barriers to and facilitators of using the Internet and mobile apps for diabetes self-management. 


\section{Conclusion}

Patients with T2DM in a developing country currently use mobile phones mostly for contacting friends and searching for information, and more than half of them have a positive attitude toward and high confidence in using smartphone apps to help manage their diabetes. The majority of patients with T2DM are inclined to use mobile phones and the Internet, especially to plan their diet, check blood glucose, and contact their doctors. The present study provides valuable information for designing and implementing interventions based on mHealth to promote self-management in T2DM.

\section{Supplementary information}

Supplementary information accompanies this paper at https://doi.org/10. 1186/s12911-020-1038-y.

Additional file 1. Final Questionnaire.

\section{Abbreviations}

apps: Applications; BMI: Body Mass Index; CVI: Content Validity Index CVR: Content Validity Ratio; eHealth: electronic Health; mHealth: mobile Health; SPSS: Statistical Package for the Social Sciences; WHO: World Health Organization

\section{Acknowledgments}

The authors would like to thank the experts who participated in the study. We would also like to extend our appreciation to the patients who participated in completing the questionnaire.

\section{Authors' contributions}

Conception and design of study (EN, FR), Development of materials (EN, RH), Data collection $(\mathrm{RH})$, Data analysis and interpretation (RSh), Drafting the article (RH, RSh), Revising article critically for important intellectual content (EN, FR), Final approval of the version to be published (EN, FR, RH RSh). All stages of this study, especially data collection and analysis, were conducted with the support of the funding body. All authors read and approved the final manuscript.

\section{Funding}

This work was supported by the Kashan University of Medical Sciences Research Council [grant number 96104].

\section{Availability of data and materials}

The datasets used and/or analysed during the current study are available from the corresponding author on reasonable request.

\section{Ethics approval and consent to participate}

Ethical approval was elicited from the Ethical Committee at the of Kashan University of Medical Sciences (IR.KAUMS.NUHEPM.REC.1396.21). All participants were invited verbally to take part in the study. For those who agreed to participate, a signed written informed consent form was obtained.

\section{Consent for publication}

Not applicable.

\section{Competing interests}

The authors declare that they have no competing interests.

\section{Author details}

${ }^{1}$ Health Information Management Research Center, School of Allied Health Professions, Kashan University of Medical Sciences, Pezeshk Blvd, 5th of Qotbe Ravandi Blvd-Pardis Daneshgah, Kashan 8715973449, Iran. ${ }^{2}$ Department of Health Information Management \& Technology, School of Allied Health Professions, Kashan University of Medical Sciences, Kashan, Iran.
${ }^{3}$ Student research committee, Kashan University of Medical Sciences, Kashan, Iran.

Received: 21 August 2019 Accepted: 28 January 2020

Published online: 07 February 2020

\section{References}

1. Shrivastava SR, Shrivastava PS, Ramasamy J. Role of self-care in management of diabetes mellitus. J Diabetes Metab Disord. 2013;12(1):14.

2. Organization WH. Global report on diabetes; 2016. p. 88.

3. Whiting DR, Guariguata L, Weil C, Shaw J. IDF diabetes atlas: global estimates of the prevalence of diabetes for 2011 and 2030. Diabetes Res Clin Pract. 2011:94(3):311-21.

4. Animaw $W$, Seyoum $Y$. Increasing prevalence of diabetes mellitus in a developing country and its related factors. PLoS One. 2017;12(11): e0187670.

5. Haghdoost A, Rezazadeh Kermani M, Sadghirad B, Baradaran H. Prevalence of type 2 diabetes in the Islamic Republic of Iran: systematic review and meta-analysis. East Mediterr Health J. 2009;15(3):591-9.

6. Diabetes Country Profiles; 2016. [https://www.who.int/diabetes/countryprofiles/en/]. Accessed 3 June 2019

7. Xu J, Murphy SL, Kochanek KD, Bastian B, Arias E. Deaths: Final data for 2016. Natl Vital Stat Rep. 2018;67(5):1-76.

8. Papatheodorou K, Banach M, Bekiari E, Rizzo M, Edmonds M. Complications of diabetes 2017. Journal of Diabetes Research. 2018;2018:4

9. American Diabetes Association. Standards of medical care in diabetes-2014. Diabetes Care. 2014;37(Supplement 1):S14-80.

10. Nadkarni A. Implementation Plans and Self-Monitoring of Blood Glucose in Diabetics. Michigan, United States: University of Michigan; 2009.

11. Cramer JA. A systematic review of adherence with medications for diabetes. Diabetes Care. 2004;27(5):1218-24.

12. Stiffler D, Cullen D, Luna G. Diabetes barriers and self-care management: the patient perspective. Clin Nurs Res. 2014;23(6):601-26.

13. Yasa I, Rahayu V, Widastra I, Labir IK, Wedri NM, Sulisnadewi NLK. Barrier of self care management on urban type 2 diabetic patients in Bali. Indian J Public Health Res Dev. 2018;9(5):363-7.

14. Peck A. Changing the face of standard nursing practice through telehealth and telenursing. Nurs Adm Q. 2005;29(4):339-43.

15. Scheibe M, Reichelt J, Bellmann M, Kirch W. Acceptance factors of mobile apps for diabetes by patients aged 50 or older: a qualitative study. Medicine. 2015:20:4(1).

16. Zolfaghari M, Mousavifar SA, Haghani H. Mobile phone text messaging and telephone follow-up in type 2 diabetic patients for 3 months: a comparative study. J Diabetes Metab Disord. 2012;11(1):7.

17. Muralidharan S, Ranjani H, Anjana RM, Allender S, Mohan V. Mobile health technology in the prevention and management of type 2 diabetes. Indian $J$ Endocrinol Metab. 2017;21(2):334.

18. Williams JLS, Walker RJ, Smalls BL, Campbell JA, Egede LE. Effective interventions to improve medication adherence in Type 2 diabetes: a systematic review. Diabetes Manag (London, England). 2014;4(1):29.

19. Zamanzadeh V, Zirak M, Maslakpak MH, Parizad N. Distance education and diabetes empowerment: a single-blind randomized control trial. Diabetes Metab Syndr. 2017;11:S247-51.

20. Holtz B, Lauckner C. Diabetes management via mobile phones: a systematic review. Telemed E Health. 2012;18(3):175-84.

21. Schnall R, Mosley JP, Iribarren SJ, Bakken S, Carballo-Diéguez A, Brown W III. Comparison of a user-centered design, self-management app to existing mHealth apps for persons living with HIV. JMIR mHealth uHealth. 2015:3(3):e91.

22. Martinez PR. A qualitative study on patient perceptions towards mHealth technology among high risk, chronic disease patients; 2015.

23. Rangraz Jeddi F, Nabovati E, Amirazodi S. Features and effects of information technology-based interventions to improve self-management in chronic kidney disease patients: a systematic review of the literature. J Med Syst. 2017;41(11):170.

24. Park S, Burford S, Hanlen L, Dawda P, Dugdale P, Nolan C, Burns J. An integrated mHealth model for type 2 diabetes patients using mobile tablet devices. J Mobile Technol Med. 2016:5(2):24-32.

25. Hoque R, Sorwar G. Understanding factors influencing the adoption of mHealth by the elderly: an extension of the UTAUT model. Int J Med Inform. 2017;101:75-84. 
26. Opoku D, Stephani V, Quentin W. A realist review of mobile phone-based health interventions for non-communicable disease management in subSaharan Africa. BMC Med. 2017;15(1):24.

27. Hofstede J, de Bie J, Van Wijngaarden B, Heijmans M. Knowledge, use and attitude toward eHealth among patients with chronic lung diseases. Int J Med Inform. 2014;83(12):967-74.

28. Boyle L, Grainger R, Hall RM, Krebs JD. Use of and beliefs about mobile phone apps for diabetes self-management: surveys of people in a hospital diabetes clinic and diabetes health professionals in New Zealand. JMIR mHealth uHealth. 2017;5(6):e85

29. Dobson KG, Hall P. A pilot study examining patient attitudes and intentions to adopt assistive technologies into type 2 diabetes self-management. J Diabetes Sci Technol. 2014;9(2):309-15.

30. Humble JR, Tolley EA, Krukowski RA, Womack CR, Motley TS, Bailey JE. Use of and interest in mobile health for diabetes self-care in vulnerable populations. J Telemed Telecare. 2016;22(1):32-8.

31. Jafari JJ, Moonaghi HK, Ahmady S, Zary N, Masiello I. Investigating readiness to use internet and mobile services of diabetic patients of a middle-income country. In: PeerJ PrePrints; 2015.

32. Hood M, Wilson R, Corsica J, Bradley L, Chirinos D, Vivo A. What do we know about mobile applications for diabetes self-management? A review of reviews. J Behav Med. 2016:39(6):981-94.

33. Yaghmaie F. Content validity and its estimation. Journal of Medical Education. 2003;3(1):25-27.

34. Wildevuur S, Thomese F, Ferguson J, Klink A. Information and communication technologies to support chronic disease self-management: preconditions for enhancing the partnership in person-centered care. J Participatory Med. 2017;9(1):e14.

35. Hodge H, Carson D, Carson D, Newman L, Garrett J. Using internet technologies in rural communities to access services: the views of older people and service providers. J Rural Stud. 2017;54:469-78.

36. Townsend L, Sathiaseelan A, Fairhurst G, Wallace C. Enhanced broadband access as a solution to the social and economic problems of the rural digital divide. Local Econ. 2013;28(6):580-95.

37. Newman LA, Biedrzycki KR, Baum F. Digital technology access and use among socially and economically disadvantaged groups in South Australia; 2010

38. Conway N, Campbell I, Forbes P, Cunningham S, Wake D. mHealth applications for diabetes: user preference and implications for app development. Health inform J. 2016;22(4):1111-20.

39. Jenkins C, Burkett N-S, Ovbiagele B, Mueller M, Patel S, Brunner-Jackson B, Saulson $\mathrm{R}$, Treiber F. Stroke patients and their attitudes toward mHealth monitoring to support blood pressure control and medication adherence. Mhealth. 2016;2:24.

40. Garcia-Zapirain B, de la Torre DI, Sainz de Abajo B, López-Coronado M. Development, technical, and user evaluation of a web mobile application for self-control of diabetes. Telemed E Health. 2016;22(9):778-85.

41. Garabedian LF, Ross-Degnan D, Wharam JF. Mobile phone and smartphone technologies for diabetes care and self-management. Curr Diabetes Rep. 2015;15(12):109.

42. Krishna S, Boren SA. Diabetes self-management care via cell phone: a systematic review. J Diabetes Sci Technol. 2008;2(3):509-17.

43. Liang X, Wang Q, Yang X, Cao J, Chen J, Mo X, Huang J, Wang L, Gu D. Effect of mobile phone intervention for diabetes on glycaemic control: a meta-analysis. Diabet Med. 2011;28(4):455-63.

44. Song H, Cramer EM, McRoy S, May A. Information needs, seeking behaviors, and support among low-income expectant women. Women Health. 2013; 53(8):824-42.

45. Sayakhot P, Carolan-Olah M. Internet use by pregnant women seeking pregnancy-related information: a systematic review. BMC Pregnancy Childbirth. 2016;16(1):65.

\section{Publisher's Note}

Springer Nature remains neutral with regard to jurisdictional claims in published maps and institutional affiliations.

Ready to submit your research? Choose BMC and benefit from:

- fast, convenient online submission

- thorough peer review by experienced researchers in your field

- rapid publication on acceptance

- support for research data, including large and complex data types

- gold Open Access which fosters wider collaboration and increased citations

- maximum visibility for your research: over $100 \mathrm{M}$ website views per year

At BMC, research is always in progress.

Learn more biomedcentral.com/submissions 